\title{
Dinâmica do crescimento do meloeiro rendilhado 'Fantasy' cultivado em substrato sob ambiente protegido
}

\author{
Danilo Mesquita Melo * \\ Hamilton César de Oliveira Charlo \\ Renata Castoldi \\ Leila Trevisan Braz \\ Universidade Estadual Paulista, Faculdade de Ciências Agrárias e Veterinárias, Campus de Jaboticabal \\ Rodovia de Acesso Paulo Donato Castellane, S/N, Zona Rural, CEP 17884-900, Jaboticabal - SP, Brasil \\ * Autor para correspondência \\ melo.agro@hotmail.com
}

Submetido em $11 / 04 / 2013$

Aceito para publicação em 05/02/2014

\section{Resumo}

Sistemas de cultivo em substrato têm sido utilizados por grande parte dos produtores de hortaliças. No entanto, ainda é necessária a obtenção de conhecimentos específicos sobre o desempenho das plantas nesses sistemas, possibilitando, assim, maior eficiência no cultivo. O objetivo deste trabalho foi caracterizar o crescimento do meloeiro rendilhado 'Fantasy' cultivado em substrato em ambiente protegido. As plantas foram cultivadas em vasos preenchidos com substrato contendo uma mistura de areia e casca de amendoim em partes iguais. A irrigação foi realizada por gotejamento com solução nutritiva recomendada para a cultura em cultivo hidropônico. Foi determinada a dinâmica de crescimento da cultura avaliando-se o número de folhas, massa seca das folhas (g), do caule (g) e dos frutos (g). Foram calculadas as taxas de crescimento absoluto da cultura; taxa de crescimento relativo; taxa assimilatória líquida; área foliar específica; razão de massa foliar; razão de massa de frutos; e razão de área foliar. Na colheita, foi avaliada a produção e qualidade dos frutos. De acordo com os resultados, verificou-se que os frutos foram responsáveis pela maior porcentagem de matéria seca acumulada na planta. As taxas de crescimento das plantas são decrescentes, principalmente, após a fase de frutificação.

Palavras-chave: Cucumis melo var. reticulatus; Areia; Casca de amendoim; Cultivo protegido

\section{Abstract}

Growth dynamic of 'Fantasy' net melon cultivated in substrate under protected cultivation. Cultivation systems on substrate have been used by a large part of vegetable producers. However, there is still a need to obtain specific knowledge on the performance of plants in these systems, thus enabling a greater effectiveness in cultivation. This paper aimed to characterize the growth of the net melon plant 'Fantasy' cultivated on substrate under a protected environment. Plants were cultivated in pots filled with substrate containing a mixture of sand and peanut shell in equal parts. Irrigation was performed by drip with the nutrient solution recommended for hydroponic cultivation. We determined the growth dynamics of the culture by quantifying the leaves and the mass of dry leaves (g), stem (g), and fruits (g). We calculated the absolute growth rate of the culture; relative growth rate; net assimilation rate; specific leaf area; leaf mass ratio; fruit mass ratio; and leaf area ratio. At 
the harvest time, we evaluated fruit yield and quality. According to the results, we found out that fruits were responsible for the highest percentage of dry matter accumulated in the plant. Plant growth rates are decreasing, especially after fructification.

Key words: Cucumis melo var. reticulates; Peanut bark; Protected cultivation; Sand

\section{Introdução}

O melão (Cucumis melo L.) é uma hortaliça-fruto muito consumida e de grande popularidade no mundo. Em volume de comercialização, o melão foi o produto mais exportado pelo Brasil, dentre as frutas e hortaliçasfruto, nos últimos anos (AGRIANUAL, 2013). A qualidade da produção brasileira tem sido influenciada pelas condições climáticas favoráveis e a evolução das técnicas de cultivo. Além da qualidade dos produtos, o aumento das exportações brasileiras também tem sido estimulado pelo fornecimento de frutos na época de entressafra em outros países (NEGREIROS et al., 2003).

A crescente demanda de melão tem gerado a expansão das áreas produtoras e estimulado a diferenciação do mercado deste fruto no Brasil. No país, apesar da predominância no consumo do melão amarelo, o consumo do melão rendilhado tem aumentado gradativamente em função das qualidades provenientes destes frutos. A melhoria da qualidade dos frutos tem estimulado os produtores a adotarem o cultivo em ambiente protegido, o qual oferece diversas vantagens em relação ao sistema tradicional, proporcionando assim frutos com melhor sabor e aspecto visual.

O cultivo de hortaliças em ambiente protegido tem aumentado consideravelmente, porém, fatores como a adubação mineral em excesso, manejo inadequado da irrigação por gotejamento e o uso contínuo do solo, têm promovido o surgimento de problemas com salinização e contaminação por fitopatógenos. Estes problemas têm estimulado a busca pelo cultivo de plantas em recipientes utilizando substrato, pois, além das diversas vantagens oferecidas por este sistema de cultivo, o uso de substrato pode ser adotado como medida preventiva para ocorrência de problemas relacionados ao solo, principalmente fitopatológicos.

Experimentos realizados em Jaboticabal-SP, os quais tiveram por objetivo avaliar o desempenho de hortaliças em diferentes substratos, verificaram que a mistura de areia e casca de amendoim, em proporções iguais, resultaram em grande produtividade e qualidade às culturas (FERNANDES et al., 2002; MELO et al., 2012). A casca de amendoim é um resíduo da agroindústria amplamente disponível na região sudeste do Brasil e a possibilidade de utilização deste material no cultivo em substrato estimulou a busca de informações sobre a viabilidade e o manejo que deve ser adotado para o melhor desenvolvimento das espécies cultivadas.

A análise da fisiologia do crescimento é uma ferramenta útil no estudo do comportamento vegetal sob diferentes condições ambientais, permitindo assim comparar o desenvolvimento das plantas em diferentes sistemas de cultivo. Estes estudos têm por objetivo avaliar o crescimento ao longo do ciclo da planta e a contribuição dos diferentes órgãos no crescimento, e em consonância com a quantificação do acúmulo de nutrientes, isso permitirá aprimorar o manejo da cultura incluindo a recomendação de adubação.

O conhecimento sobre o crescimento de plantas permite planejar métodos racionais de cultivo, contribuindo na expressão do potencial genético, e, possibilitando assim, o fornecimento de dados para construção de modelos matemáticos que são utilizados para descrever o crescimento das plantas (CASTOLDI et al., 2009). Para Charlo et al. (2011), a produção econômica de uma cultivar é determinada em função das interações planta-ambiente, e, para a compreensão da natureza interna de uma cultivar, é necessário, além da produção o conhecimento de outros fatores.

Para Larcher (2000), os índices fisiológicos obtidos na análise de crescimento indicam a capacidade do sistema assimilatório das plantas em sintetizar (fonte) e alocar a matéria orgânica, nos diversos órgãos (drenos) que dependem da fotossíntese, respiração e translocação de fotoassimilados dos sítios de fixação de carbono aos locais de utilização ou armazenamento, onde ocorrem o crescimento e a diferenciação dos órgãos. Além 
disso, a determinação de um modelo de crescimento e o conhecimento de seus índices fisiológicos podem auxiliar na obtenção de um programa de nutrição mais eficiente e direcionado à idade e aos órgãos envolvidos na produtividade e qualidade de frutos.

Dessa forma, o objetivo do presente trabalho foi caracterizar o crescimento do meloeiro rendilhado, híbrido 'Fantasy', cultivado em substrato composto por areia e casca de amendoim com fertirrigação, sob ambiente protegido.

\section{Material e Métodos}

O trabalho foi desenvolvido no Setor de Olericultura e Plantas Aromático-Medicinais, pertencente à Faculdade de Ciências Agrárias e Veterinárias (UNESP - FCAV), Campus de Jaboticabal-SP. A altitude local é de 614 m; com coordenadas geográficas aproximadas de: latitude $21^{\circ} 14^{\prime}$ 'S e longitude $48^{\circ} 17^{\prime} \mathrm{W}$.

O experimento foi conduzido em casa de vegetação do tipo arco, com $30 \mathrm{~m}$ de comprimento e $6 \mathrm{~m}$ de largura, pé direito de $3,5 \mathrm{~m}$, tela de proteção lateral com $50 \%$ de sombreamento e teto coberto com filme de polietileno de baixa densidade, com 150 micrômetros de espessura. $\mathrm{O}$ delineamento experimental foi em blocos casualizados com quatro repetições. A área experimental constou de 150 plantas (96 avaliadas e 54 bordaduras), sendo retiradas quatro plantas por bloco em cada época de amostragem.

Utilizou-se o híbrido 'Fantasy', proveniente da empresa TAKII SEED. De acordo com a empresa, o híbrido possui resistência a Oídio e Fusarium, peso médio de frutos em torno de $1,5 \mathrm{~kg}$, crescimento vigoroso e tolerância ao frio, frutos com casca de coloração verde e polpa verde brilhante, formato arredondado, $14^{\circ}$ a $15^{\circ}$ brix e colheita com 50 a 57 dias após o florescimento. A semeadura foi realizada no dia 12 de janeiro de 2010, em bandejas de poliestireno expandido de 128 células, utilizando substrato comercial. O transplante ocorreu 24 dias após a semeadura quando as mudas apresentaram a primeira folha definitiva completamente expandida. As plantas foram cultivadas em vasos plásticos com 31,3 $\mathrm{cm}$ e 22,1 cm de diâmetro nas partes superior e inferior, respectivamente; $27,5 \mathrm{~cm}$ de altura e capacidade total de
$13,0 \mathrm{dm}^{3}$, os quais foram preenchidos com substrato. A distância entre os vasos foi estabelecida de forma que a medida entre os centros correspondesse ao espaçamento de $1,0 \mathrm{~m}$ entre fileira e $0,5 \mathrm{~m}$ entre plantas.

O substrato utilizado foi a mistura de areia e casca de amendoim em volumes iguais. A areia foi adquirida em estabelecimentos específicos para construção civil, sendo conhecida como areia média. Já a casca de amendoim foi obtida junto à COPLANA (Cooperativa dos plantadores de cana da zona de Guariba), a qual processa e comercializa amendoim, gerando grandes quantidades deste resíduo anualmente. Após a obtenção da casca de amendoim, esta foi seca em temperatura ambiente, triturada, passada em peneira com abertura de $6 \mathrm{~mm}$ x $18 \mathrm{~mm}$, e então armazenada em local seco.

A irrigação foi realizada por gotejamento, por meio de gotejadores do tipo aranha, com solução nutritiva recomendada para a cultura em cultivo hidropônico (CASTELLANE; ARAÚJO, 1994), sendo a composição dos macronutrientes e micronutrientes, em g.L $\mathrm{L}^{-1}$, de: 178 (N); 93 (P); 265 (K); 153 (Ca); 21,6 (Mg); 28,9 (S); 0,30 (B); 2,35 (Fe); 0,35 (Mn); 0,23 (Zn); 0,03 (Cu) e 0,04 (Mo).

A fertirrigação foi controlada por um temporizador, tendo início às $7 \mathrm{~h}$ e término às $18 \mathrm{~h}$. O sistema era ativado automaticamente de acordo com a hora e tempo de funcionamento programado. A programação e a lâmina de água aplicada foram definidas de acordo com a idade da cultura e a drenagem mínima dos vasos. Nos primeiros 15 dias após o transplante (DAT) as taxas de aplicação média por irrigação foram de $84 \mathrm{~mL} / \mathrm{h}$, dos 15 aos 30 DAT foram de $98 \mathrm{~mL} / \mathrm{h}$, dos 30 aos 40 DAT foram de $126 \mathrm{~mL} / \mathrm{h}$, dos 40 aos 50 DAT foram de 140 $\mathrm{mL} / \mathrm{h}$, dos 50 aos 60 DAT foram de $182 \mathrm{~mL} / \mathrm{h}$ e a partir dos 60 DAT foram de $210 \mathrm{~mL} / \mathrm{h}$.

Durante o cultivo, as plantas foram tutoradas com fitilhos plásticos até a altura de 2,2 $\mathrm{m}$ do solo, quando então se realizou a eliminação da dominância apical. Foi conduzida uma planta por vaso, adotando-se desbrota e raleio. A desbrota foi realizada até o $10^{\circ}$ entrenó, mantendo-se as hastes laterais dos entrenós $11^{\circ}, 12^{\circ}$ e $13^{\circ}$, onde ocorreu a frutificação. Após a fixação dos frutos, determinada quando estes apresentavam em 
média 3,0 cm de diâmetro, foi eliminada umas destas hastes laterais, deixando apenas dois frutos por planta. Nas hastes laterais mantiveram-se duas folhas após os frutos, bem como aquelas anteriores a estes, sendo para isso realizado a eliminação da dominância apical da haste. A desbrota das hastes secundárias continuou sendo realizada nos entrenós acima e abaixo dos frutos.

Foram realizadas coletas de quatro plantas em seis épocas para a determinação da dinâmica de crescimento da cultura do melão. A primeira ocorreu 14 DAT, e as posteriores em intervalos de 14 dias. A última avaliação foi antecipada em decorrência da colheita dos frutos, sendo realizada oito dias após a penúltima avaliação. Em cada época, as plantas amostradas foram retiradas dos vasos, dividida em caule, folha e fruto. Em seguida, foi determinada a área foliar e os órgãos foram secos e pesados. Na mesma data foram avaliadas as características do crescimento: número de folhas, e posteriormente foi realizada a mensuração da massa seca das folhas, do caule e de frutos. De posse dos dados, foram calculadas as taxas de crescimento absoluto da cultura (TCA); taxa de crescimento relativo (TCR); taxa assimilatória líquida (TAL); razão de área foliar (RAF); área foliar específica (AFE); razão de massa foliar (RMF) e razão de massa de frutos (RMFt), conforme metodologia descrita por Evans (1972) e Benincasa (2003).

Os dados utilizados para confecção das curvas de crescimento foram submetidos à análise de variância seguida de análise de regressão, sendo considerada como variável independente a idade da planta, expressa em dias, após o transplante. Para estas análises foi utilizada a função logística, a qual é amplamente empregada para representar dados de crescimento de animais e vegetais (HOFFMAN; VIEIRA, 1977).

A colheita ocorreu aos 78 dias após o transplante (DAT), ou 102 dias após a semeadura (DAS), quando os frutos apresentaram-se maduros. O ponto de colheita foi determinado pelo início da formação da camada de abscisão junto ao pedúnculo e pela alteração de cor do epicarpo.

Foram amostradas cinco plantas de cada bloco para a avaliação dos frutos. Os frutos colhidos foram levados para o Laboratório de Produtos Hortícolas do Departamento de Produção Vegetal, onde foram avaliadas as seguintes características: massa fresca do fruto $(\mathrm{kg})$; diâmetro médio transversal e longitudinal do fruto $(\mathrm{cm})$, e diâmetro médio transversal e longitudinal do lóculo $(\mathrm{cm})$ (utilizando paquímetro digital); índice de formato de fruto (IFF) e índice de formato do lóculo (obtido pela razão entre médias dos diâmetros longitudinais e transversais), onde frutos com formato esféricos possuem IFF $=1$, oblongos IFF $=1,1$ a 1,7 e achatados IFF $<1,0$; espessura do mesocarpo (cm) (utilizando paquímetro digital). Para características qualitativas avaliaram-se: sólidos solúveis ( ${ }^{\circ}$ Brix); $\mathrm{pH}$, determinado no extrato do suco, com auxílio de peagâmetro digital; acidez titulável (\% de ácido cítrico); vitamina $\mathrm{C}$ (mg de ácido ascórbico/100 mL de suco); firmeza do fruto $(\mathrm{N})$, obtido através de um penetrômetro digital; rendilhamento de casca, determinado por avaliação visual de acordo com a escala de notas adotada por Rizzo (2004), sendo 1-fraco, 2- médio e 3-intenso; índice de maturação (RATIO), dado através da relação $\mathrm{SS} / \mathrm{AT}$. Destes dados foram extraídos as médias e estabelecido o desvio padrão médio $(\delta)$.

Foi realizada a caracterização química do substrato antes e após o cultivo, utilizando o método de extração 1:1,5 v/v, proposto por Sonneveld et al. (1974). Antes do cultivo, o substrato possuía as seguintes características químicas: $0,16 \mathrm{dS} \cdot \mathrm{m}^{-1}$ (condutividade elétrica); 6,35 (pH); 1,74 mg. $\mathrm{L}^{-1}\left(\mathrm{~N}-\mathrm{NH}_{4}^{+}\right), 5,45 \mathrm{mg} . \mathrm{L}^{-1}\left(\mathrm{~N}-\mathrm{NO}_{3}{ }^{-}\right)$, 0,61 mg. $\mathrm{L}^{-1}(\mathrm{P}), 26,53 \mathrm{mg} \cdot \mathrm{L}^{-1}(\mathrm{~K}), 3,4 \mathrm{mg} \cdot \mathrm{L}^{-1}(\mathrm{Ca}), 1,55$ mg.L.- $(\mathrm{Mg}) ; 1,23 \mathrm{mg} . \mathrm{L}^{-1}(\mathrm{~S}), 0,050 \mathrm{mg} . \mathrm{L}^{-1}(\mathrm{~B}), 0,010$ mg.L. $\mathrm{L}^{-1}(\mathrm{Cu}), 0,572 \mathrm{mg} . \mathrm{L}^{-1}(\mathrm{Fe}), 0,019 \mathrm{mg} \cdot \mathrm{L}^{-1}(\mathrm{Mn})$ e $0,008 \mathrm{mg} \cdot \mathrm{L}^{-1}(\mathrm{Zn})$.

Os dados climáticos foram aferidos através de um termo-higrômetro, localizado em abrigo de madeira, a 1,5 m do solo, no interior da casa de vegetação.

\section{Resultados e Discussão}

A análise química do substrato verificada no ato da colheita demonstrou os seguintes resultados: 0,28 dS.m ${ }^{-1}$ (condutividade elétrica); 5,05 (pH); 2,13 mg.L${ }^{1}\left(\mathrm{~N}-\mathrm{NH} 4^{+}\right) ; 25,31 \mathrm{mg} . \mathrm{L}^{-1}\left(\mathrm{~N}^{-N^{-}}{ }_{3}^{-}\right) ; 3,83 \mathrm{mg} . \mathrm{L}^{-1}(\mathrm{P}) ; 33,62$ mg.L. $\mathrm{L}^{-1}(\mathrm{~K}) ; 42,71 \mathrm{mg} . \mathrm{L}^{-1}(\mathrm{Ca}) ; 4,44 \mathrm{mg} \cdot \mathrm{L}^{-1}(\mathrm{Mg}) ; 9,85$ mg. $\mathrm{L}^{-1}(\mathrm{~S}) ; 0,067 \mathrm{mg} \cdot \mathrm{L}^{-1}(\mathrm{~B}) ; 0,006 \mathrm{mg} \cdot \mathrm{L}^{-1}(\mathrm{Cu}) ; 0,333$ mg. $\mathrm{L}^{-1}(\mathrm{Fe}) ; 0,190 \mathrm{mg} . \mathrm{L}^{-1}(\mathrm{Mn})$ e 0,040 mg. $\mathrm{L}^{-1}(\mathrm{Zn})$. 
Comparando as análises realizadas antes e após a execução do experimento, é possível verificar que houve acúmulo expressivo de nutrientes no substrato em decorrência principalmente da fertirrigação. Fernandes et al. (2002), avaliando as modificações químicas de diferentes substratos para a cultura do tomateiro, verificaram aumento nos teores dos nutrientes, $\mathrm{pH}$ e condutividade elétrica do substrato no final do cultivo comparados aos observados no início. Da mesma forma, Cardoso (2009), ao reutilizar a fibra da casca de coco, no cultivo do meloeiro rendilhado, também verificou aumentos expressivos nos teores de nutrientes presentes no substrato no momento da colheita. Embora ocorra extração de grande parte dos nutrientes fornecidos pela fertirrigação, o excedente pode ser drenado ou acumulado nos vasos. Caso ocorra acúmulo excessivo de fertilizantes no substrato, há grandes possibilidades de ocorrer absorção excessiva de nutrientes pelas plantas, causando toxicidade e diminuição na produtividade e qualidade dos frutos, além da perda desnecessária de fertilizantes e contaminação do meio ambiente (KAWAKAMI et al., 2007). No entanto, os resultados verificados no presente trabalho, indicam que, apesar de verificar aumento nos teores de nutrientes após o término do cultivo, o manejo da fertirrigação foi adequado para o bom desenvolvimento das plantas, além disso, a técnica de drenagem mínima possibilitou a diminuição do descarte da solução nutritiva não absorvida pelas plantas.

As temperaturas médias do ar, em função da data de coleta das plantas, obtidas durante o período experimental foram: $29,8^{\circ} \mathrm{C} ; 30,5^{\circ} \mathrm{C} ; 28,2^{\circ} \mathrm{C} ; 28,5^{\circ} \mathrm{C}$; $23,5^{\circ} \mathrm{C}$ e $27,0^{\circ} \mathrm{C}(0-14,14-28,28-42,42-56,56-70$ e 70-78 dias após o transplante, respectivamente). Com relação à umidade relativa do ar média, foram verificados os seguintes valores: $67,3 \% ; 68,3 \% ; 67,2 \% ; 71,3 \%$; $73,2 \%$ e $60,8 \%(0-14,14-28,28-42,42-56,56-70$ e $70-$ 78 dias após o transplante, respectivamente).

A colheita ocorreu 78 DAT ou 102 dias após a semeadura (DAS), obtendo-se produtividade média de $70.120 \mathrm{~kg} \mathrm{ha}^{-1}$ de frutos (considerando estande de 20.000 plantas/ha). Durante o ciclo, observou-se que houve acúmulo crescente de matéria seca total da parte aérea (MST), com 99,9\% do valor máximo acumulado sendo atingido aos 76 DAT (100 DAS), correspondendo a aproximadamente 180 g.planta ${ }^{-1}$ (Figura 1-A). De

FIGURA 1: Acúmulo de massa seca total (MST), massa seca de folhas (MSF), massa seca de hastes (MSH), massa seca de frutos (MSFt) (1-A), massa fresca de frutos (MFF) (1-B), em meloeiro rendilhado 'Fantasy' cultivado em substrato, em função da idade da planta.UNESP-FCAV, Jaboticabal-SP, 2013.

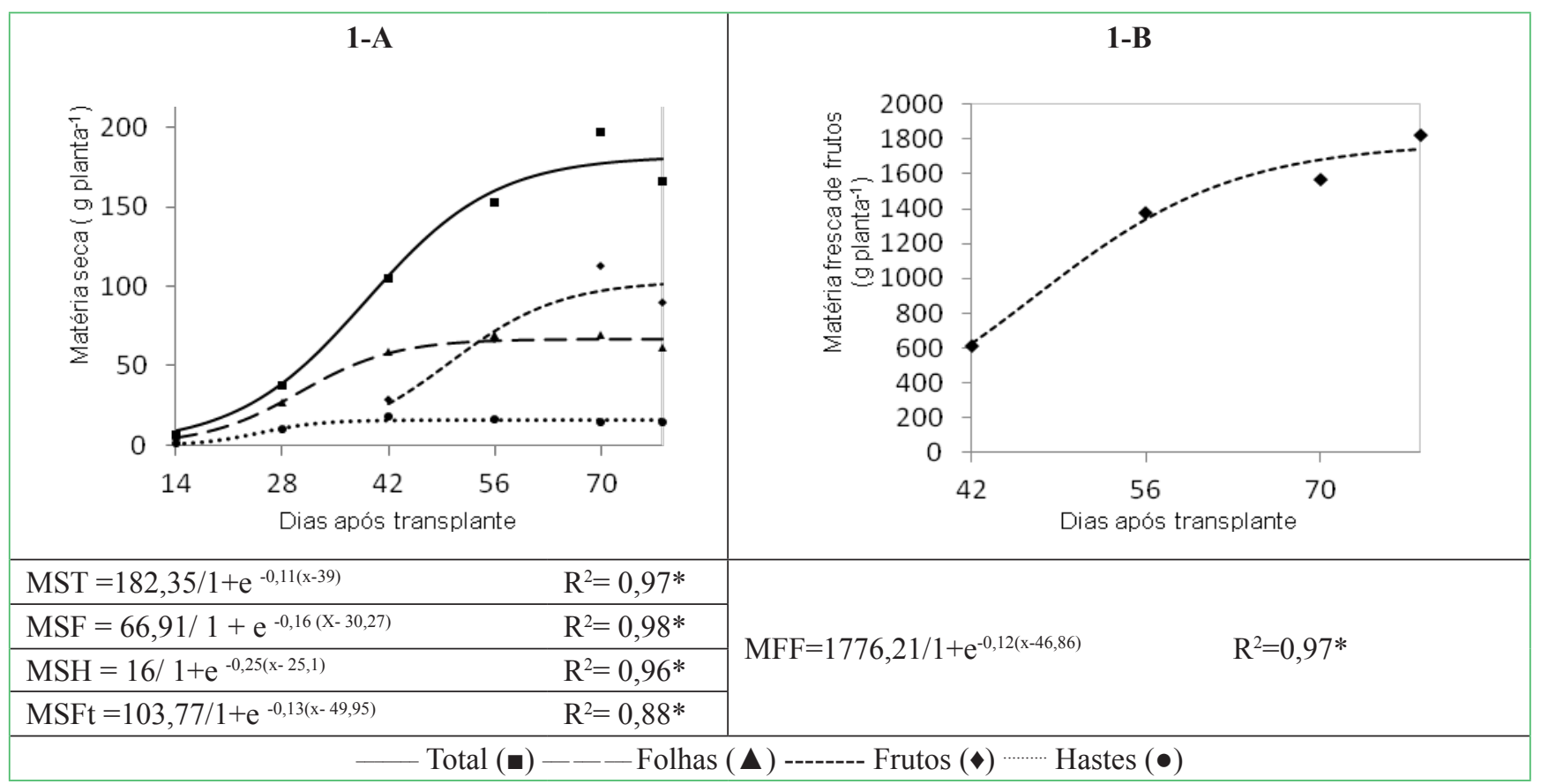

* significativo ao nível de $5 \%$ de probabilidade $(0.01=<\mathrm{p}<0.05)$. 
acordo com Gurgel et al. (2010), trabalhos realizados em Mossoró-RN, com variedades de meloeiro, sob diversas condições ambientais, apresentaram curvas de acúmulo de matéria seca com três estágios bem definidos, em que o primeiro apresenta taxa de acumulação lenta, o segundo é um período de rápido crescimento e no terceiro a taxa de acúmulo diminui em relação ao segundo, sendo então, semelhante à dinâmica de crescimento verificada no presente trabalho. A definição destes estágios possibilita a adoção de melhores estratégias culturais objetivando atender as necessidades fisiológicas da cultura.

O acúmulo de maior expressão na matéria seca total ocorreu, aproximadamente, entre 30 e 55 DAT. A partir de 55 DAT, observou-se que os frutos foram responsáveis pelo maior acúmulo de matéria seca na planta, sendo o único órgão a manter contínuo crescimento (Figura 1-A). No cultivo do meloeiro rendilhado, é comum a estabilização e redução do acúmulo de matéria seca da porção vegetativa das plantas após o início da frutificação.

Costa et al. (2006), ao avaliarem doses de fósforo na solução nutritiva, no cultivo do meloeiro rendilhado, híbrido Bônus $n^{\circ} 2$, cultivado em hidroponia no sistema NFT (Nutrient film technique), em Jaboticabal-SP, verificaram acúmulo de matéria seca total de 178,12 g. planta $^{-1}$. Estes autores também observaram que aos 45 DAT houve redução no incremento de matéria seca das folhas e hastes, e aumento na matéria seca de frutos, o que, segundo os autores, é resultado das relações fonte e dreno e da redistribuição de nutrientes na planta em função da maior demanda pelos frutos.

Ao final do ciclo, os frutos participaram com $54,11 \%$ da matéria seca total da planta. As folhas contribuíram com $36,92 \%$, e hastes com $8,96 \%$, da matéria seca total. Gurgel et al. (2010), ao avaliarem o acúmulo de matéria seca e de nutrientes em meloeiro amarelo produzido sob estresse salino e doses de potássio, verificaram que os frutos respondem por $73,33 \%$ da matéria seca da parte aérea ao se aplicar $328 \mathrm{~kg} \cdot \mathrm{ha}^{-1}$ de $\mathrm{K}_{2} \mathrm{O}$ ao final dos 63 DAS.

$\mathrm{O}$ acúmulo de matéria seca nas folhas (MSF) foi estabilizado em aproximadamente 58 DAT (82 DAS), mantendo-se a massa seca de aproximadamente 66 g.planta ${ }^{-1}$ (Figura 1-A). As hastes contribuíram em menor proporção para o acúmulo de matéria seca da planta. A partir de 36 DAT há uma estabilização na quantidade de matéria seca total acumulada nestes órgãos, permanecendo em torno de 16 g.planta ${ }^{-1}$ até o fim do ciclo (Figura 1-A).

A identificação do ponto de colheita do meloeiro rendilhado é dificilmente detectada em função das poucas modificações externas que ocorrem nos frutos nas últimas fases de crescimento e acúmulo de sólidos solúveis. Apesar de empresas responsáveis pelos híbridos recomendarem uma data para início da colheita, o crescimento e o desenvolvimento dos frutos estão intimamente relacionados ao ambiente, cultivar, manejo, entre outros fatores. Dessa forma, a idade da planta se torna uma técnica pouco precisa na hora de identificar o momento ideal para colher, sendo mais seguro avaliar as características químicas (teor de sólidos solúveis, acidez titulável e índice de maturação) e visuais (coloração da casca, formação da zona de abscisão, dentre outros) através da amostragem de frutos. A formação da zona de abscisão junto ao pedúnculo foi a característica visual tomada como base para o início da colheita dos frutos neste experimento, a qual, demostrou indicar boas características qualitativas.

Na colheita, a qual ocorreu 50 dias após a antese, verificou-se que os frutos obtiveram em média 101,58 g de matéria seca por planta. Já para matéria fresca, os frutos obtiveram em média 1,75 kg (Figura 1-B). Analisando-se as variáveis de matéria seca e fresca dos frutos, verifica-se que estes são compostos por menos de $10 \%$ de matéria seca, sendo a outra parte composta por água. Aos 42 DAT, os frutos eram compostos por 4,03\% de massa seca. No ato da colheita, essa taxa aumentou para $5,85 \%$ de matéria seca. Apesar deste pequeno acréscimo de matéria seca, este resultado demonstra que os frutos ainda possuem grande quantidade de água, o que os torna importante para o consumo humano.

Com relação ao número de folhas nas plantas coletadas observou-se uma grande variação durante o ciclo, o que foi resultado do manejo da poda, a qual era realizada de acordo com o crescimento das hastes secundárias (Figura 2-A). Neste sistema de cultivo tenta-se manter um determinado número de folhas por 
planta, o que varia de acordo com a idade destas. No presente trabalho, observou-se completa estabilização no número de folhas a partir dos 18 DAT, mantendo-se, aproximadamente, 30 folhas na planta até o final do ciclo (Figura 2-A). Deste número, 22 folhas eram provenientes da haste principal, e as oito folhas restantes, dos ramos laterais onde foram mantidos os frutos.

No que concerne à área foliar, verificou-se que desde o transplante a área foliar permaneceu em constante crescimento até, aproximadamente, 53 DAT (77 DAS) (Figura 2-B). De acordo com a função logística, o valor máximo para área foliar foi obtido aos 62 DAT (86 DAS), sendo 7.443,82 $\mathrm{cm}^{2}$. Em outro experimento, o híbrido Bônus $n^{\circ} 2$, cultivado em solo, no período compreendido entre o inverno e a primavera, em Jaboticabal-SP, a maior área foliar $\left(6.103 \mathrm{~cm}^{2}\right.$.planta $\left.{ }^{-1}\right)$ foi obtida aos 91 DAT (CANATO, 2002).

A dinâmica de crescimento da área foliar ocorreu em função da redistribuição de fotoassimilados para os frutos. Esta hipótese é reforçada ao observar o acúmulo de matéria seca nas folhas, onde a estabilização desta característica coincide com a estabilização da área foliar, indicando que a partir deste período os frutos tornam-se drenos preferenciais. Medidas na nutrição direcionada aos frutos, a partir desta data, podem ser tomadas, tornando o sistema mais eficiente com relação ao uso de fertilizantes.

Como verificado, a manutenção do número de folhas na planta não diminuiu a expansão da área foliar até os 53 DAT. O crescimento individual das folhas provavelmente foi influenciado positivamente pela poda dos ramos laterais. Nestes casos, provavelmente, há maior redistribuição de nutrientes para as folhas remanescentes da haste principal promovendo assim sua maior expansão espacial.

Apesar do crescente acúmulo de matéria seca da maioria dos órgãos, foi observado que, no geral, as taxas de crescimento permaneceram em decréscimo ao longo do ciclo (Tabela 1). Após o início da frutificação, o desenvolvimento vegetativo diminuiu em função da redistribuição de nutrientes e fotoassimilados para os frutos, além disso, a poda de ramos laterais e apical limitou o seu crescimento. A diminuição da velocidade de crescimento no final do ciclo pode ser influenciada também pela senescência foliar e maior incidência de fitopatógenos.

A taxa de crescimento absoluto (TCA) máxima foi verificada aos 42 DAT, diminuindo a partir desta data (Tabela 1). A TCA é uma característica que expressa a

FIGURA 2: Número de folhas (NF) (2-A) e área foliar (AF) (2-B), em meloeiro rendilhado 'Fantasy' cultivado em substrato, em função da idade da planta. UNESP-FCAV, Jaboticabal-SP, 2013.

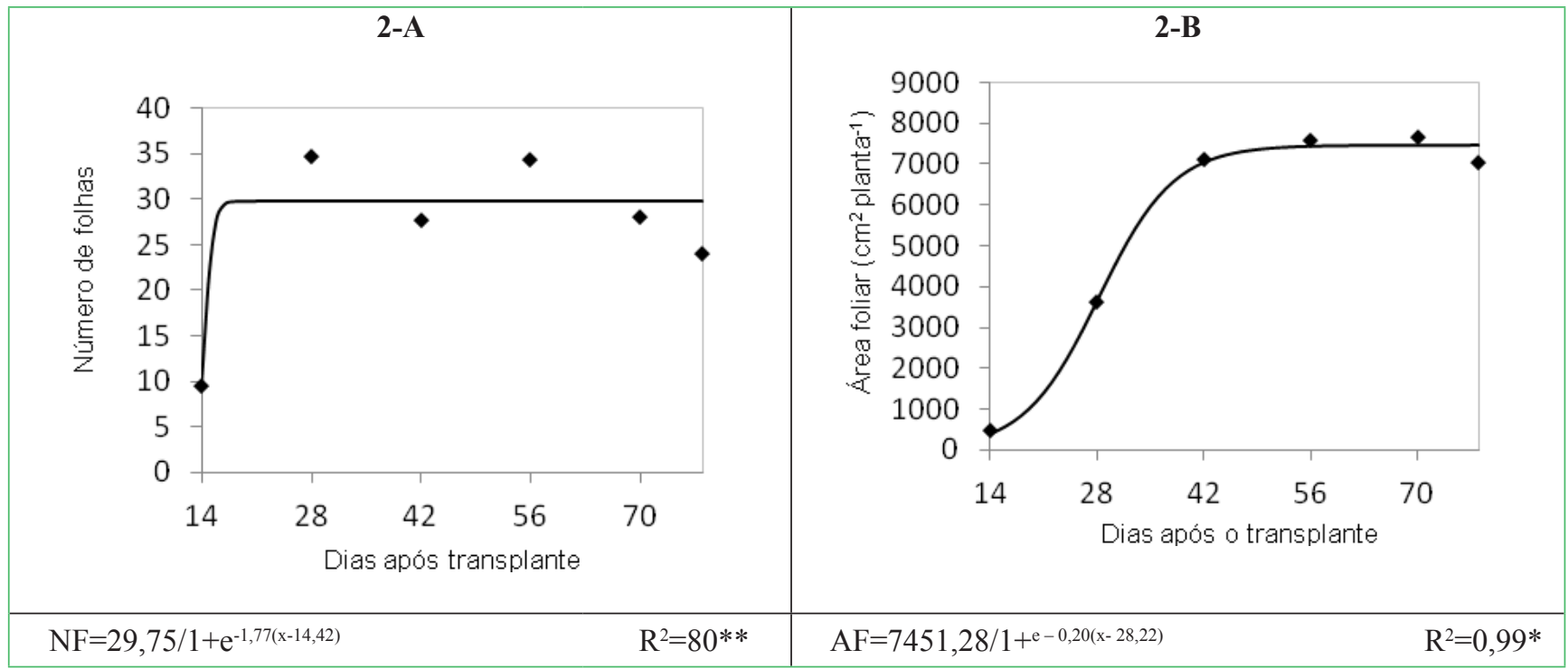

** significativo ao nível de $1 \%$ de probabilidade $(\mathrm{p}<0.01)$. 
TABELA 1: Taxa de crescimento absoluto (TCA), taxa de crescimento relativo (TCR), taxa assimilatória líquida (TAL), razão de área foliar (RAF), área foliar específica (AFE), razão de massa foliar (RMF) e razão de massa de frutos (RMFt), em meloeiro rendilhado 'Fantasy', cultivado em substrato. UNESPFCAV. Jaboticabal-SP. 2013.

\begin{tabular}{|c|c|c|c|c|c|c|c|}
\hline Dias & $\begin{array}{c}\text { TCA } \\
\text { (g.planta- }^{-1} \text {.dia) }\end{array}$ & $\begin{array}{c}\text { TCR } \\
(\text { g.g.-1.dia) }\end{array}$ & $\begin{array}{c}\text { TAL } \\
(\text { g.cm } \\
\text {-2.dia })\end{array}$ & $\begin{array}{c}\text { RAF } \\
\left(\mathrm{cm}^{2} \cdot \mathrm{g}^{-1}\right)\end{array}$ & $\begin{array}{c}\mathrm{AFE} \\
\left(\mathrm{cm}^{2} \cdot \mathrm{g}^{-1}\right)\end{array}$ & RMF & RMFt \\
\hline 14 DAT & - & - & - & 70,1377 & 88,9686 & 0,7883 & - \\
\hline 28 DAT & 2,1804 & 0,1211 & 0,0197 & 96,4719 & 134,2956 & 0,7184 & - \\
\hline 42 DAT & 4,8552 & 0,0740 & 0,0132 & 67,3537 & 120,9543 & 0,5569 & 0,2738 \\
\hline 56 DAT & 3,3862 & 0,0265 & 0,0064 & 49,5321 & 108,5239 & 0,4564 & 0,4369 \\
\hline 70 DAT & 3,1891 & 0,0184 & 0,0060 & 38,8218 & 110,7507 & 0,3505 & 0,5737 \\
\hline 78 DAT & $-3,5260$ & $-0,0194$ & $-0,0043$ & 42,5223 & 115,1722 & 0,3692 & 0,5411 \\
\hline
\end{tabular}

DAT: dias após transplante.

velocidade de crescimento das plantas (BENINCASA, 2003). Taxas de crescimento absoluto semelhantes foram obtidas por Canato (2002), em Jaboticabal, ao avaliar o crescimento de híbridos de melão rendilhado em duas épocas de cultivo. No período compreendido entre a primavera-verão, este autor verificou nos híbridos Bônus $\mathrm{n}^{\circ} 2$ e Mission, crescimento lento aos 20 DAT (0, 035 g.planta.dia ${ }^{-1}$ e 0,033 g.planta.dia ${ }^{-1}$, respectivamente), e em seguida, aos 40 DAT, aumento significativo (1,340 g.planta.dia ${ }^{-1}$ e 0,956 g.planta.dia ${ }^{-1}$ ), sendo que partir desse período, foi constatado decréscimos nas taxas, chegando a ser negativa na última avaliação $(-0,129$ g.planta.dia ${ }^{-1}$ e $-0,001$ g.planta.dia $\left.{ }^{-1}\right)$. Vidigal et al. (2007), ao avaliarem o crescimento da abóbora híbrida tipo tesukabuto, verificaram que a taxa de crescimento máxima observada $\left(124,21\right.$ g.planta.dia $\left.{ }^{-1}\right)$ ocorreu aos 74 dias após a semeadura (DAS), diminuindo a partir de então até a colheita (98 DAS).

A taxa de crescimento relativo (TCR) mantevese sempre em contínuo decréscimo durante o ciclo (Tabela 1). Esta taxa indica a quantidade de matéria seca produzida por unidade de matéria seca existente. O decréscimo da TCR com a idade da planta é resultado, em parte, do aumento gradativo de tecidos não fotossintetizantes com o desenvolvimento da planta (REYES-CUESTA et al., 1995). Braga et al. (2008), ao avaliarem o crescimento da melancia Mickylee, cultivada sob fertirrigação, observaram que as maiores taxas de crescimento absoluto e relativo obtidas foram, respectivamente 6,96 g.planta.dia ${ }^{-1}$ e 0,16 g.g $\mathrm{g}^{-1} \cdot \mathrm{dia}^{-1}$.
A taxa assimilatória líquida (TAL) decresceu até por volta dos 56 DAT, período em que as taxas passaram a se manter praticamente estáveis até o final do ciclo, tornando-se negativa no ato da colheita (Tabela 1). A TAL representa a taxa de fotossíntese líquida para a produção de matéria seca, além de fornecer o balanço entre o material produzido pela fotossíntese e o perdido por meio da respiração, expressando desta forma, a eficiência das folhas na produção de massa seca (BENINCASA, 2003).

A razão de área foliar (RAF) diminuiu a partir dos 28 DAT e manteve-se praticamente estável até o fim do ciclo (Tabela 1). Esta taxa demonstra a área foliar útil para a fotossíntese e o crescimento da planta, ou seja, é a área foliar utilizada para produzir $1 \mathrm{~g}$ de matéria seca (BENINCASA, 2003). A diminuição da RAF ao longo do ciclo, normalmente é consequência do autosombreamento das folhas, provocando assim diminuição da área foliar útil. Com relação à área foliar específica (AFE), verificou-se que houve oscilações durante todo o ciclo (Tabela 1). A área foliar específica é o componente morfológico e anatômico da RAF, porque relaciona a superfície com o peso de matéria seca da própria folha (BENINCASA, 2003). De acordo com a mesma autora, oscilações nesta característica são comuns e difíceis de serem interpretadas, pois estes valores são resultantes das taxas de crescimento das folhas individuais, as quais foram influenciadas pela prática da poda.

A razão de massa de folhas (RMF) determina a quantidade de matéria seca acumulada pelas folhas 
em função da matéria seca acumulada na planta toda. Estas taxas representam a matéria seca não exportada pelas folhas, dessa forma, à medida que as taxas diminuem, maior está sendo a exportação de matéria seca para outros órgãos da planta. No presente trabalho, verificou-se queda nestas taxas a partir dos 42 DAT, período em que os frutos estavam em pleno crescimento (Tabela 1). Provavelmente, a queda das taxas de RMF deve-se à exportação de nutrientes e fotoassimilados aos frutos. Isto é verificado ao observar as taxas de razão de massa de fruto (RMFt), em que houve aumento gradual no decorrer do seu desenvolvimento, demonstrando assim a maior contribuição em matéria seca para a planta.

As características produtivas proveniente dos frutos estão contidas na Tabela 2. A massa média de frutos (MMF) obtida neste trabalho, foi superior ao verificado em outros experimentos com o meloeiro rendilhado (CASTOLDI et al., 2008; CHARLO et al., 2009; ITO et al., 2009). Vargas et al. (2008), utilizando a fibra da casca de coco como substrato no cultivo de híbridos de meloeiro rendilhado, obtiveram frutos com massa média fresca de $1,25 \mathrm{~kg}_{\text {fruto }}{ }^{-1}$, sendo também inferior ao encontrado na presente pesquisa. A massa média do fruto é uma característica influenciada pela interação do genótipo com o ambiente. Alguns nichos de mercado optam por frutos com menor massa fresca visando o consumo imediato deste, sendo esta, uma característica que podem ser exploradas em função do mercado consumidor. Da mesma forma, os diâmetros transversal (DTF) e longitudinal (DTL) do fruto demonstram as dimensões destes, características que podem ser explorada em função da preferência do consumidor. Ito et al. (2009) obtiveram frutos do meloeiro rendilhado
'Bônus no 2' com menores dimensões aos verificados neste trabalho.

$\mathrm{O}$ índice de formato de fruto (IFF) demonstrou que estes possuem forma achatada. Esta característica é mais importante na disposição dos frutos em embalagens, possibilitando facilitar o transporte ou armazenamento. Para Pádua et al. (2003), frutos esféricos são os mais adequados na disposição em embalagens e no transporte.

As características de diâmetro transversal de lóculo (DTL), diâmetro longitudinal de lóculo (DLL), e índice de formato de lóculo (IFL), indicam as dimensões e formato da cavidade interna dos frutos. Estas características, em consonância com a espessura de polpa (EP), determinam o aproveitamento de polpa nos frutos, e, normalmente, são caracteres inerentes ao genótipo. Melo et al. (2012), ao avaliar a produtividade de híbridos de meloeiro rendilhado em diferentes substratos, verificaram que frutos do híbrido Fantasy possuem melhor aproveitamento de polpa, independente do substrato utilizado.

As características inerentes à qualidade dos frutos estão contidas na Tabela 3. O teor de sólidos solúveis $\left({ }^{\circ}\right.$ Brix $)$, é, certamente, a característica mais apreciada pelo consumidor. No presente trabalho, o teor de sólidos solúveis foi menor ao disseminado pela empresa comercializadora da cultivar. Na literatura é possível encontrar informações que conferem determinados valores aos genótipos, porém, esta característica pode ser influenciada em função do uso de fertilizantes, micronutrientes, temperatura e intensidade luminosa, área foliar, estádio de maturação, entre outros (SILVA et al., 2002). O pH e a acidez titulável (AT) verificada

TABELA 2: Médias de oito características produtivas avaliadas no melão rendilhado 'Fantasy', cultivado em substrato. UNESP-FCAV. Jaboticabal-SP. 2013.

\begin{tabular}{ccccccccc}
\hline & $\begin{array}{c}\text { MFF } \\
\left.\text { (kg.fruto }^{-1}\right)\end{array}$ & DTF $(\mathbf{m m})$ & DLF $(\mathbf{m m})$ & IFF & DTL (mm) & DLL (mm) & IFL & EM (mm) \\
\hline Médias & 1,75 & 151,83 & 144,94 & 0,95 & 72,51 & 75,67 & 1,04 & 43,12 \\
\hline EPM $\delta$ & 4,20 & 4,69 & 6,08 & 3,46 & 9,19 & 10,22 & 6,07 & 3,34 \\
\hline
\end{tabular}

MFF- Massa fresca do fruto; DTF- Diâmetro transversal do fruto; DLF- Diâmetro longitudinal do fruto; IFF- Índice de formato de fruto; DTL- Diâmetro transversal do lóculo; DLL- Diâmetro longitudinal do lóculo; IFL- Índice de formato do lóculo; EM- espessura do

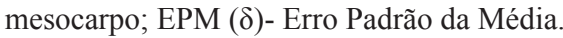


TABELA 3: Médias de sete características qualitativas avaliadas no melão rendilhado 'Fantasy', cultivado em substrato. UNESP-FCAV. Jaboticabal-SP, 2013.

\begin{tabular}{cccccccc} 
& $\begin{array}{c}\text { SS } \\
\left({ }^{\circ} \text { Brix }\right)\end{array}$ & pH & $\begin{array}{c}\text { AT \% } \\
\text { (ácido cítrico) }\end{array}$ & IM & FIRMEZA(N) & Vit. C & RC \\
\hline Médias & 10,2 & 5,03 & 0,21 & 48,57 & 18,95 & 36,48 & 3,0 \\
\hline EPM $\delta$ & 0,49 & 0,07 & 0,68 & 10,09 & 2,51 & 0,09 & 0,0 \\
\hline
\end{tabular}

SS - Sólidos solúveis; AT - Acidez titulável; IM - índice de maturação (RATIO); Vit.C - vitamina C (mg ac. ascórbico/100 mL suco); FIRMEZA (N), pH - potencial hidrogeniônico; RC - Rendilhamento de casca (notas: 1 - fraco, 2 - médio e 3 - intenso); EPM ( $\delta$ ) - Erro Padrão da Média.

nos frutos não difere do encontrado por outros autores (CASTOLDI et al., 2008; VARGAS et al., 2008; CHARLO et al., 2009). Estas características normalmente estão relacionadas com a maturação do fruto em função da utilização de ácidos orgânicos na atividade respiratória, a qual intensifica-se com o crescimento e desenvolvimento destes e após a colheita (CHITARRA; CHITARRA, 2005).

O índice de maturação (IM) está diretamente relacionado com a precocidade dos frutos, sendo que, maiores valores indicam o ponto de colheita ideal para consumo. No presente trabalho, o valor obtido para esta característica é considerado baixo, o que, provavelmente, permitiria a manutenção do fruto por mais dias na planta. Porém, considerando o tempo de conservação pós-colheita até o consumo, índices de maturação muito elevados podem não ser desejáveis para comercializar frutos que não irão ser consumidos imediatamente.

Assim como o $\mathrm{pH}$ e a acidez titulável, a firmeza da polpa dos frutos é outra característica que diminui com a maturação destes. Valores baixos indicam grande degradação celular e assim menor qualidade de polpa. Medeiros et al. (2011) obtiveram frutos do moleiro rendilhado com firmeza de $25,85 \mathrm{~N}$, sendo considerado, pelos autores, como bons para comercialização.

Com relação à vitamina $\mathrm{C}$, acredita-se que teores desta substância contidos nos frutos estão principalmente relacionados ao genótipo. A quantidade verificada nos frutos são semelhantes ao obtido por outros autores (CASTOLDI et al., 2008; CHARLO et al., 2009).

O rendilhamento da casca dos frutos (RC) observado no experimento demostrou que estes possuem boa aparência para comercialização. Esta característica é uma dos maiores atrativos visuais deste tipo de melão, sendo associado muitas vezes ao sabor pelos consumidores.

A partir dos resultados, foi possível concluir que o meloeiro rendilhado 'Fantasy', cultivado no substrato composto por areia e casca de amendoim, em ambiente protegido, possui fisiologia do crescimento semelhante aos demais sistemas de cultivo. O padrão de crescimento apresentado proporcionou elevada produtividade e qualidade de frutos, sendo, então, possível sua utilização como modelo para tomada de decisões no cultivo desta espécie e realização de demais estudos.

\section{Agradecimentos}

À Fundação de Amparo à Pesquisa do Estado de São Paulo (FAPESP) pelo auxílio à pesquisa, sob processo $n^{\circ}$ 2008/51229-0.

\section{Referências}

AGRIANUAL. Anuário da agricultura brasileira 2013. São Paulo: FNP Consultoria \& Agroinformativo, 2013.

BENINCASA, M. M. P. Análise de crescimento de plantas (noções básicas). Jaboticabal: FUNEP, 2003. 41p.

BRAGA, D. F.; NEGREIROS, M. Z.; LOPES, W. A. R.; TEÓFILO, T. M. S.; FREITAS, F. C. L.; GRANGEIRO, L. C.; ALVES, S. S. V. Crescimento de melancia 'Mickylee' cultivada sob fertirrigação. Horticultura Brasileira, Brasília, v. 26, p. 5119-5124, 2008.

CANATO, G. H. D. Crescimento e produção de híbridos de melão rendilhado, em casa de vegetação, em duas épocas de cultivo. 2002. 52 f. Trabalho de Graduação (Curso de Agronomia) - Faculdade de Ciências Agrárias e Veterinárias, Universidade Estadual Paulista, Jaboticabal. 2002.

CARDOSO, A. F. Desempenho de híbridos de melão rendilhado cultivados em substrato da fibra da casca de coco reutilizada. 2009. Dissertação (Mestrado em Produção Vegetal) - Faculdade de 
Ciências Agrárias e Veterinárias, Universidade Estadual Paulista, Jaboticabal, 2009.

CASTEllane, P. D; ARAÚJO, J. A. C. Cultivo sem solo: hidroponia. Jaboticabal: FUNEP, 1994. 43 p.

CASTOLDI, R.; CHARLO, H. C. O.; VARGAS, P. F.; BRAZ, L. T. Qualidade de frutos de cinco híbridos de melão rendilhado em função do número de frutos por planta. Revista Brasileira de Fruticultura, Jaboticabal, v. 30, p. 455-458, 2008.

CASTOLDI, R.; CHARLO, H. C. O.; VARGAS, P. F.; BRAZ, L. T. Crescimento, acúmulo de nutrientes e produtividade da cultura da couve-flor. Horticultura Brasileira, Brasília, v. 27, n. 4, p. 438446, 2009.

CHARLO, H. C. O.; CASTOLDI, R.; VARGAS, P. F.; BRAZ, L. T. Desempenho de híbridos de melão-rendilhado cultivados em substrato. Científica, Jaboticabal, v. 37, p. 16-21, 2009.

CHARLO, H. C. O.; OLIVEIRA, S. F.; CASTOLDI, R.; VARGAS, P. F.; BRAZ, L. T.; BARBOSA, J. C. Growth analysis of sweet pepper cultivated in coconut fiber in a greenhouse. Horticultura Brasileira, Brasília, v. 29, n. 3, p. 316-323, 2011.

CHITARRA, M. I. F.; CHITARRA, A. B. Pós-colheita de frutos e hortaliças: fisiologia e manuseio. Lavras: UFLA, 2005. 783 p.

COSTA, C. C.; CECÍlIO FILHO, A. B.; REZENDE, B. L. A.; BARBOSA, J. C. Crescimento e partição de assimilados em melão cantaloupe em função de concentrações de fósforo em solução nutritiva. Científica, Jaboticabal, v. 34, n. 1, p. 123-130, 2006.

EVANS, G. C. The quantitative analysis of plant growth. Oxford: Blackwell Scientific Publications. 1972. 734 p.

FERNANDES, C.; ARAÚJO, J. A. C.; CORÁ, J. E. Impacto de quatro substratos e parcelamento da fertirrigação na produção de tomate sob cultivo protegido. Horticultura Brasileira, Brasília, v. 20, n. 4, p. 559-563, 2002.

GURGEL, M. T.; GHEYI, H. R.; OLIVEIRA, FÁBIO, H. T. Acúmulo de matéria seca e nutrientes em meloeiro produzido sob estresse salino e doses de potássio. Revista Ciência Agronômica, v. 41, n. 1, p. 18-28, 2010.

HOFFMANN, R.; VIEIRA, S. Análise de regressão - uma introdução à econometria. São Paulo: HUCITEC-EDUSP, 1977. p. 399.

ITO, L. A.; CHARLO, H. C. O.; CASTOLDI, R.; BRAZ, L. T.; CAMARGO, M. Seleção de porta-enxertos resistente ao cancro da haste e seus efeitos na produtividade de melão 'Bônus $\mathrm{n}^{\circ} 2$ '. Revista Brasileira de Fruticultura, Jaboticabal, v. 31, n. 1, p. 262267, 2009

KAWAKAMI, F. P. C.; ARAUJO, J. A. C.; IUNCK, V.; FACTOR, T. L.; CORTEZ, G. E. P. Manejo da fertirrigação em função da condutividade elétrica da solução nutritiva drenada no cultivo de tomate cereja sob ambiente protegido. 2006. In: CONGRESSO BRASILEIRO DE OLERICULTURA, 47, 2007, Porto Seguro. Resumos... Vitória da conquista: ABH, 2007. Versão eletrônica.
LARCHER, W. Ecofisiologia vegetal. São Carlos: Rima, 2000. $531 \mathrm{p}$.

MEdeIROS, D. C.; MEDEIROS, J. F.; PEREIRA, F. A. L.; SOUZA, R. O.; SOUZA, P. A. Produção e qualidade de melão cantaloupe cultivado com água de diferentes níveis de salinidade. Revista Caatinga, Mossoró, v. 24, n. 1, p. 92-98, 2011.

MELO, D. M.; CASTOLDI, R.; CHARLO, H. C. O.; GALATTI, F. S.; BRAZ, L. T. Produção e qualidade de melão rendilhado sob diferentes substratos em cultivo protegido. Revista Caatinga, Mossoró, v. 25, n. 1, p. 58-66, 2012.

NEGREIROS, M. Z.; MEDEIROS, J. F.; SALES JÚNIOR, R.; MENEZES, J. B. Cultivo de melão no pólo agrícola Rio Grande do Norte/Ceará. Horticultura Brasileira, Brasília, v. 21, n. 3, 2003.

PÁDUA, J. G.; BRAZ, L. T.; BANZATTO, D. A.; GUSMÃO, S. A. L.; GUSMÃO, M. T. A. Net melon cultivars productivity under different cultivation systems, during summer and winter. Acta Horticulturae, Amsterdam, v. 607, p. 83-89, 2003.

REYES-CUESTA, R.; LOPES, N. F.; OLIVA, M. A.; FRANCO, A. A. Crescimento e conversão da energia solar em Phaseolus vulgares em função da fonte de nitrogênio. Revista Ceres, Viçosa, v. 2, n. 2, p. 405-455, 1995.

RIZZO, A. A. do N. Obtenção e avaliação de genótipos de melão rendilhado em ambiente protegido. 2004. $38 \mathrm{f}$. Tese (Doutorado em Agronomia - Área de Concentração em Produção Vegetal) Universidade Estadual Paulista. Jaboticabal. 2004.

SILVA, P. S. L.; SÁ. W. R.; MARIGUELE, K. H.; BARBOSA, A. P. R.; OLIVEIRA, O. F. Distribuição do teor de sólidos solúveis totais em frutos de algumas espécies de clima temperado. Revista Caatinga, Mossoró, v. 15, n. 1, p. 19-23, 2002.

SONNEVELD, C.; ENDE, J. V. D.; DIJK, P. A. V. Analysis of growing media by means of a 1:1,5 volume extract. Communications in Soil Science and Plant Analysis, New York, v. 5, n. 3, p. 183-202, 1974.

VARGAS, P. F.; CASTOLDI, R.; CHARLO, H. C. O.; BRAZ, L. T. Desempenho de cultivares de melão rendilhado em função do sistema de cultivo. Horticultura Brasileira, Brasília, v. 26, p. $197-$ 201, 2008.

VIDIGAL, S. M.; PACHECO, D. D.; FACION, C. E. Crescimento e acúmulo de nutrientes pela abóbora híbrida tipo Tetsukabuto.

Horticultura Brasileira, Brasília, v. 25, p. 375-380, 2007. 